\title{
EFEKTIVITAS MODUL PEMBELAJARAN BERBASIS PROYEK SEBAGAI SUMBER BELAJAR SISWA SMK
}

\author{
Leila Fajrie Auddiena Nuriel Fath Albana \\ Program Studi Informatika, Univeristas Indraprasta PGRI \\ Email: leilfanfa@gmail.com
}

\begin{abstract}
Abstrak
Modul berbasis proyek dalam proses pembelajaran di Sekolah Menengah Kejuruan (SMK) banyak dimanfaatkan sebagai salah satu sumber belajar yang diterapkan untuk meningkatkan kualitas pembelajaran siswa. Tujuan penelitian ini adalah mendeskripsikan keefektifan modul pembelajaran berbasis proyek sebagai sumber belajar dalam meningkatkan hasil belajar siswa pada mata pelajaran Produktif Multimedia. Penelitian ini menggunakan pendekatan kuasi eksperimen dengan nonequivalent control group design yang melibatkan 63 siswa SMK Muhammadiyah Wonosari. Instrumen yang digunakan adalah berupa soal pretest dan soal posttest. Teknik analisis data untuk mengetahui signifikansi dan efektivitas pada penelitian ini menggunakan Uji- $t$ dan Gain Score. Hasilnya terdapat perbedaan hasil belajar yang signifikan antara siswa yang menggunakan modul dengan siswa yang menggunakan metode konvensional dengan taraf signifikasi 0,005 serta modul pembelajaran berbasis proyek sebagai sumber belajar siswa SMK terbukti cukup efektif untuk meningkatkan hasil belajar siswa pada mata pelajaran Produktif Multimedia dengan hasil gain score sebesar 0,669 yang tergolong kategori sedang.
\end{abstract}

Kata Kunci : Efektivitas, Modul Pembelajaran, Hasil Belajar

\begin{abstract}
Project-based modules in the learning process in Vocational High Schools are widely used as a learning resource that is applied to improve the quality of student learning. The purpose of this study is to describe the effectiveness of project-based learning modules as a learning resource in improving student learning outcomes in Multimedia Productive subjects. This study uses a quasi-experimental approach with nonequivalent control group design involving 63 students of Muhammadiyah Wonosari Vocational High School. The instruments used were in the form of pretest and posttest questions. Data analysis techniques to determine the significance and effectiveness of this study using the T-Test and Gain Score. The result showed there were significant differences in learning outcomes between students who used modules and students who used conventional methods with a significance level of 0.005 and project-based learning modules as a source of learning for vocational students to prove effective enough to improve student learning outcomes in Productive Multimedia subjects with a gain score of 0,669 which was classified as medium category.
\end{abstract}

Key Words : Effectiveness, Project-Based Modules, Learning Outcomes

\section{PENDAHULUAN}

Jenjang pendidikan vokasi khususnya siswa SMK menghadapi tantangan besar untuk menyambut derasnya perkembangan dan daya saing di era globalisasi. Semakin meningkatnya standar sumber daya manusia yang dibutuhkan untuk mengimbangi perkembangan jaman, membuat kepercayaan diri khususnya pada siswa SMK semakin menurun saat ini. Oleh karena itu, keterampilan abad 21 yaitu berpikir kritis, kolaborasi, komunikasi, dan kreativitas sangat dibutuhkan untuk meningkatkan skill sebagai bekal bekerja nantinya. Ketrampilan tersebut sangat penting ditumbuhkembangkan agar mampu menghadapi tantangan abad 21 khususnya dalam dunia kerja.

Kualitas individu siswa sangat berpengaruh terhadap pemilihan strategi pengelolaan. Aspek tersebut berkaitan dengan bagaimana merancang konsep pembelajaran khususnya komponen strategi pembelajaran serta sumber belajar 
agar sesuai dengan karakteristik siswa [1]. Perilaku dan karakteristik awal siswa hendaknya harus relevan dengan proses pembelajaran yang dilaksanakan [2]. Karakteristik siswa berpengaruh terhadap bakat, motivasi belajar, atau kemampuan awal yang telah dimiliki sebelumnya [1].

Mata pelajaran Produktif Multimedia merupakan salah satu mata pelajaran kompetensi kejuruan pada program keahlian Multimedia kelas X di SMK Muhammadiyah Wonosari. Mata pelajaran ini difokuskan pada pembelajaran terkait bidang multimedia sebagai bakal peserta didik untuk menghadapi dunia kerja. Mata pelajaran Produktif Multimedia menjadi salah mata pelajaran yang memiliki daya tarik yang cukup kuat karena seiring perkembangan zaman, pengetahuan yang diperoleh dari mata pelajaran ini memberikan peluang dan harapan yang menguntungkan di masa mendatang. Hal tersebut didukung dengan diselenggarakannya SMK dengan kompetensi keahlian Mutimedia sebanyak 90 sekolah se-Yogyakarta yang tersebar di lima kabupaten [3].

Salah satu masalah belajar yang dialami siswa pada mata pelajaran Produktif Multimedia adalah peralihan metode pembelajaran dari sistem konvensional ke pembelajaran yang berpusat pada siswa. SMK menerapkan project-based learning dengan tujuan untuk mengasah kemampuan praktik siswa agar mampu bersaing di dunia industri. Sesuai tujuan Sekolah Menengah Kejuruan yang menekankan pada aspek keterampilan tanpa mengesampingkan aspek lain, model pembelajaran yang banyak digunakan adalah project-based learning. Penerapan model ini disesuaikan dengan salah satu tujuanya itu membekali siswa dengan kemampuan ilmu pengetahuan dan teknologi serta kecakapan kejuruan para profesi sesuai dengan kebutuhan masyarakat. [4]. Model pembelajaran project-based learning ( $\mathrm{PjBL})$ adalah suatu metode pengajaran sistematis yang melibatkan para siswa dalam mempelajari pengetahuan dan keterampilan melalui proses yang terstruktur, pengalaman nyata dan teliti yang dirancang untuk menghasilkan produk [5].

Siswa belum memanfaatkan modul pembelajaran yang ada dengan maksimal sehingga mereka masih mengalami kesulitan dalam proses pembelajaran. Padahal modul pembelajaran merupakan salah satu sumber belajar penunjang tersebut sangat dibutuhkan karena akan membantu siswa dalam memahami, mengingat, dan mengulangi pelajaran yang telah disampaikan sebelumnya. Penggunaan modul pembelajaran dengan menetapkan pengajaran dan pembelajaran kontekstual harus dimaksimalkan untuk mencapai tujuan pembelajaran [6]. Selain itu, hasil belajar siswa juga belum optimal, hal ini ditunjukkan dengan masih terdapat kurang lebih $65 \%$ siswa yang mendapatkan nilai dibawah KKM. Penelitian mengungkap bahwa hasil belajar dipengaruhi oleh faktor persepsi penguasaan metode mengajar praktik guru, persepsi media pembelajaran, dan motivasi belajar siswa yang dijalankan secara bersama-sama [7]. Oleh karena itu, perancangan pembelajaran dengan mengkolaborasikan secara maksimal aspek-aspek yang terlibat perlu diperhatikan dengan baik.

Berdasarkan permasalahan yang telah dijabarkan, untuk meningkatkan hasil belajar siswa SMK Muhammadiyah Wonosari, diperlukan perancangan konsep pembelajaran yang matang dengan memanfaatkan media modul pembelajaran berbasis proyek yang telah tersedia di sekolah. Modul sebagai salah satu sumber belajar yang memfasilitasi proses pembelajaran agar siswa lebih mudah 
memahami dan mengingat materi yang telah disampaikan. Modul menjadi salah satu sumber belajar yang sesuai karena modul mendukung pembelajaran praktik maupun teori. Siswa dapat belajar secara optimal dan meyesuaikan kecepatan belajar dengan kemampuan masingmasing. Penggunaan modul pada proses pembelajarandapat meningkatkanhasil belajar yang dicapai oleh siswa [8]. Kolaborasi model pembelajaran berbasis modul juga efektif dalam meningkatkan pemahaman konsep dan keterampilan generik siswa yang secara tidak langsung berdampak pada hasil belajarnya [9]. Model PjBL memberikan keleluasaan kepada siswa untuk menentukan sendiri proyek yang akan dikerjakan mulai dari perencanaan hingga hasil akhir produk yang dikembangkan. Peran guru dalam konteks ini adalah sebagai fasilitator, menyediakan resources dan pengalaman bekerja, mendorong siswa berdiskusi dan memecahkan masalah, serta memastikan siswa tetap antusias selama proses pengerjaan proyek berlangsung.

Maka dari itu, tujuan penelitian ini adalah mendeskripsikan keefektifan modul pembelajaran berbasis proyek sebagai sumber belajar dalam meningkatkan hasil belajar siswa pada mata pelajaran Produktif Multimedia. Pembelajaran menggunakan modul pembelajaran dapat memfasilitasi siswa untuk mengasah kemampuan belajarnya sesuai dengan kecepatan masing-masing yang dapat dilakukan kapanpun dan dimanapun sehingga mendukung pembelajaran mandiri tanpa bantuan fasilitator secara langsung.

\section{METODE}

Penelitian ini menggunakan pendekatan kuasi eksperimen dengan nonequivalent control group design. Subjek penelitian yaitu 63 siswa SMK Muhammadiyah Wonosari kompetensi keahlian Multimedia
Kelas $\mathrm{X}$ Semester 2 tahun ajaran 2016/2017 yang dibagi menjadi kelompok kontrol dan kelompok eksperimen. Desain penelitian dijelaskan dalam tabel sebagai berikut.

Tabel 1. Skema Nonequivalent Control Group Design

\begin{tabular}{lccc}
\hline \multicolumn{1}{c}{ Grup } & Pretest & Perlakuan & Posttest \\
\hline $\begin{array}{l}\text { Kelompok } \\
\begin{array}{l}\text { Eksperimen } \\
\text { Kelompok }\end{array}\end{array}$ & $\mathrm{O}_{1}$ & $\mathrm{x}$ & $\mathrm{O}_{2}$ \\
Kontrol & $\mathrm{O}_{3}$ & - & $\mathrm{O}_{4}$ \\
\hline
\end{tabular}

Keterangan :

$\mathrm{O}_{1}$ : Hasil pretest kelompok eksperimen

$\mathrm{O}_{2}$ : Hasil posttest kelompok eksperimen

$\mathrm{O}_{3}$ : Hasil pretest kelompok kontrol

$\mathrm{O}_{4}$ : Hasil posttest kelompok kontrol

$\mathrm{X}$ : Perlakuan

Teknik pengumpulan data menggunakan instrumen pretest dan posttest yang diterapkan pada kelompok eksperimen dan kelompok kontrol. Teknik analisis data pada penelitian ini adalah teknik analisis data kuantitatif. Data yang diperoleh diolah menggunakan uji- $t$ untuk mengetahui ada tidaknya perbedaan antara hasil belajar siswa yang diberikan perlakuan menggunakan modul dan tanpa modul sebagai sumber belajar. Uji-t dalam penelitian ini menggunakan Uji- $t$ separated varians. Harga uji-t hasil perhitungan dikonsultasikan dengan harga $t_{\text {tabel }}$ pada taraf signifikansi $5 \%$.

Gain-score digunakan untuk mengetahui keefektifan penggunaan modul pembelajaran berbasis proyek dalam upaya meningkatkan hasil belajar siswa. Uji gain adalah selisih antara nilai posttest dan pretest yang didapat dengan rumus sebagai berikut.

$$
\begin{aligned}
& \text { Gain }=\frac{\text { skor posttest }- \text { skor pretest }}{\text { skor ideal }- \text { skor pretest }} \\
& \text { Sumber:[10] }
\end{aligned}
$$

Langkah selanjutnya setelah mendapatkan data hasil pengolahan kemudian 
menentukan kriteria efektivitas penggunaan modul pembelajaran berdasarkan kategori sebagai berikut.

Tabel 2. Pengkategorian Hasil Analisis Menggunakan Gain Score

\begin{tabular}{cc}
\hline Nilai & Kategori \\
\hline $\mathrm{g} \geq 0,7$ & Tinggi(Efektif) \\
$0,7>\mathrm{g} \geq 0,3$ & Sedang(Cukup Efektif) \\
$\mathrm{g}<0,3$ & Rendah(Tidak Efektif) \\
\hline & Sumber: [11]
\end{tabular}

\section{HASIL DAN PEMBAHASAN}

Subjek uji coba pada penelitian ini adalah siswa SMK Muhammadiyah Wonosari, berdasarkan data hasil belajar siswa pada mata pelajaran Produktif Multimedia yang masih tergolong rendah. Sebelum melaksanakan pretest dan posttest pada kelompok eksperimen dan kelompok kontrol, terlebih dahulu dilakukan uji instrumen penelitian. Pengujian instrumen ini menggunakan uji validitas, realibilitas, daya pembeda, dan taraf kesukaran. Pengujian instrumen ini bertujuan agar instrumen yang digunakan dalam penelitian ini memiliki validitas soal yang baik, realibel, memiliki daya beda yang dapat membedakan siswa yang berkemampuan rendah, sedang, dan tinggi juga memiliki tingkat kesukaran yang tinggi atau rendah. Hasil dari uji validitas menunjukan hasil nilai Alpha-Cornbach 0,926 dimana lebih besar dari 0,7 dan soal dikatakan reliabel. Uji daya beda dikategorikan cukup dan baik sebanyak 11 soal, serta baik sekali sebanyak 8 soal. Uji taraf kesukaran dikategorikan mudah sebanyak 25 soal, dan sedang sebanyak 5 soal.

Tahap selanjutnya dilakukan uji prasyarat untuk mengetahui peningkatan hasil belajar siswa setelah menggunakan modul pembelajaran. Uji prasyarat yang digunakan adalah uji normalitas dan uji homogenitas. Pada uji normalitas didapat soal pretest dan posttest pada seluruh kelas dikategorikan data terdistribusi normal dengan skor pretest kelas eksperimen 0,213,pretest kelas kontrol 0,298 . Hasil posttest kelas eksperimen 0,377 dan posttest kelas kontrol 0,714. Pada uji homogenitas data bersifat homogen dengan uji homogenitas pretest 0,974 dan posttest 0,056. Setelah instrumen selesai diuji, kemudian dilaksanakan kegiatan pengambilan data kepada kelompok eksperimen dan kelompok kontrol mulai dari pelaksanaan pretest, pembelajaran empat kali tatap muka menggunakan modul pembelajaran berbasis proyek, kemudian melaksanakan posttest.

Data yang diperoleh secara keseluruhan menggambarkan bahwa sekitar $79 \%$ siswa memberikan respon yang baik dengan penggunaan modul berbasis proyek sebagai sumber belajar yang dapat memotivasi siswa, memberikan panduan, dan dapat menyesuaikan kecepatan belajar. Hasil rata-rata skor pretest disajikan pada tabel berikut.

Tabel 3. Rerata Skor Pretest

\begin{tabular}{lcccc}
\hline & N & $\begin{array}{l}\text { Minima } \\
\text { l }\end{array}$ & $\begin{array}{l}\text { Maksima } \\
\text { l }\end{array}$ & $\begin{array}{l}\text { Rerat } \\
\mathbf{a}\end{array}$ \\
\hline Eksperime & 3 & 30 & 80 & 49,56 \\
n & 2 & & & \\
Kontrol & 3 & 27 & 77 & 46,10 \\
& 1 & & & \\
\hline
\end{tabular}

Berdasarkan tabel di atas, rerata skor pretest untuk kelompok eksperimen adalah 49,56. Distribusi frekuensi skor pretest kelompok eksperimen disajikan pada grafik berikut.

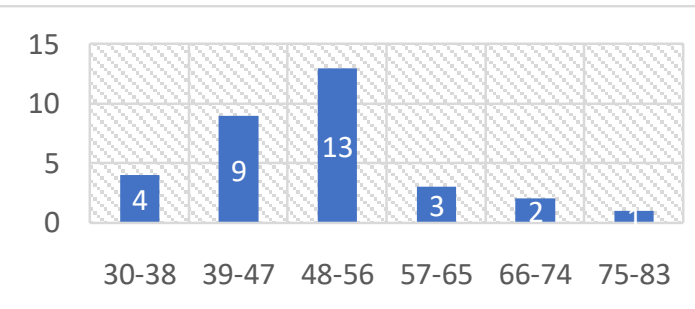

Gambar 1. Grafik Distribusi Frekuensi Skor Pretest Kelompok Eksperimen 
Sedangkan rerata skor pretest untuk kelas kontrol adalah 46,10 dengan distribusi frekuensi skor pretest kelompok kontrol disajikan pada grafik berikut.

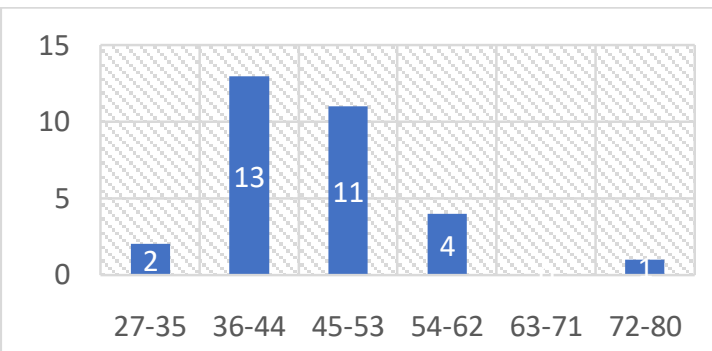

Gambar 2. Grafik Distribusi Frekuensi Skor Pretest Kelompok Kontrol

Berdasarkan kedua grafik di atas tidak terjadi perbedaan yang signifikan antara kedua kelompok setelah diberikan pretest.

Setelah modul pembelajaran berbasis proyek diterapkan pada kelompok eksperimen, terlihat perbedaan yang dapat sajikan pada tabel berikut.

Tabel 4. Rerata Skor Posttest

\begin{tabular}{|c|c|c|c|c|}
\hline & $\mathbf{N}$ & $\begin{array}{l}\text { Minima } \\
\text { l }\end{array}$ & $\begin{array}{l}\text { Maksima } \\
\text { l }\end{array}$ & $\begin{array}{l}\text { Rerat } \\
\text { a }\end{array}$ \\
\hline Eksperime & $\begin{array}{l}3 \\
2\end{array}$ & 40 & 100 & 82,81 \\
\hline Kontrol & $\begin{array}{l}3 \\
1\end{array}$ & 57 & 90 & 73,55 \\
\hline
\end{tabular}

Tabel di atas menunjukkan bahwa rerata skor posstest untuk kelompok eksperimen mengalami peningkatan yang signifikan yaitu 82,81. Distribusi frekuensi skor posttest kelompok eksperimen disajikan pada grafik berikut.

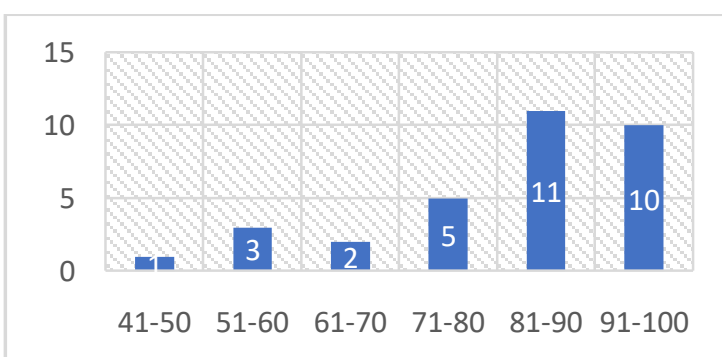

Gambar 3. Grafik Distribusi Frekuensi Skor Posttest Kelompok Eksperimen
Kelompok kontrol yang tidak mendapatkan perlakuan menghasilkan rerata 73,55 dimana tidak menunjukkan peningkatan yang signifikan. Distribusi frekuensi skor posttest kelompok kontrol disajikan pada grafik berikut.

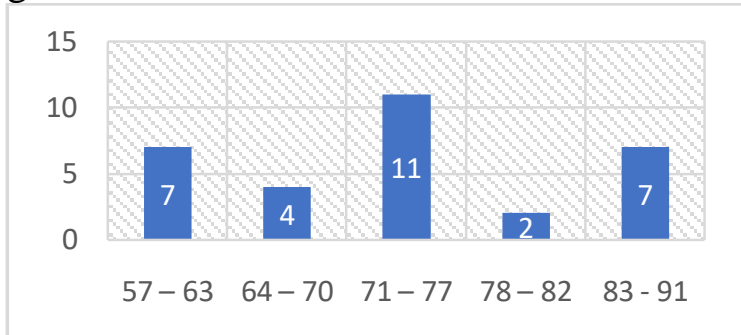

\section{Gambar 4. Grafik Distribusi Frekuensi Skor Posttest Kelompok Kontrol}

Grafik di atas menunjukkan bahwa 51\% skor posttest siswa untuk kelompok kontrol masih di bawah KKM sedangkan $78 \%$ skor posttest siswa untuk kelompok eksperimen berada pada sebaran di atas KKM.

Uji- $t$ pada penelitian ini digunakan untuk melihat perbedaan hasil belajar siswa. Hasil uji- $t$ didapat bahwa $t_{\text {hitung }}$ pada kelompok posttest adalah 2.888 dan nilai signifikasinya 0,005 dimana lebih kecil dari 0,05 , sehingga dapat disimpulkan bahwa terdapat perbedaan antara pembelajaran menggunakan metode konvensional dan pembelajaran menggunakan modul pembelajaran berbasis proyek sebagai sumber belajar siswa.

Tahapan selanjutnya adalah melakukan uji $n$-gain untuk mengetahui keefektifan modul pembelajaran berbasis proyek untuk meningkatkan hasil belajar. Hasil dari uji gain adalah sebagai berikut.

$$
\begin{aligned}
\text { Gain } & =\frac{82,81-49,58}{100-49,58} \\
& =0,669
\end{aligned}
$$

Hasil n-gain diperoleh nilai gain yaitu 0,669 . Jika diinterpretasikan berdasarkan Tabel 2, maka nilai tersebut termasuk 
dalam kriteria sedang $(0,7>g>0,3)$. Hasil nilai gain menunjukkan bahwa ada peningkatan dalam skor hasil belajar siswa antara sebelum pembelajaran menggunakan sebelum dengan setelah menggunakan modul pembelajaran berbasis proyek. Hal ini menunjukkan bahwa pembelajaran dengan menggunakan modul berbasis proyek sebagai sumber belajar yang telah dikembangkan sebelumnya cukup efektif untuk meningkatkan hasil belajar siswa pada mata pelajaran Produktif Multimedia.

Hasil uji efektivitas tersebut sejalan dengan penelitian yang menyataan bahwa implementasi pembelajaran menggunakan modul dapat meningkatkan hasil belajar siswa SMKN 13 Kota Malang [12]. Selain dapat meningkatkan hasil belajar siswa, modul pembelajaran juga dapat dikemas dengan lebih modern sehingga dapat memotivasi siswa untuk belajar [13]. Penerapan modul dengan konsisten dan terarah juga mampu meningkatkan kreativitas siswa SMK dalam mengembangkan ide-ide pada kegiatan praktiknya. Beberapa hasil penelitian yang relevan tersebut, memperkuat bukti bahwa penggunaan modul pembelajaran berbasis proyek mampu meningkatkan hasil belajar siswa SMK.

Dampak yang dirasakan dengan adanya penerapan modul pembelajaran berbasis proyek sebagai sumber belajar adalah pembelajaran berjalan dengan efektif dan efisien. Tujuan pembelajaran dapat dicapai dengan optimal dan sesuai dengan waktu yang telah ditargetkan. Selain itu, dengan bantuan sumber belajar yang memotivasi, siswa mendapatkan pengalaman belajar yang lebih bermakna sehingga informasi dapat disimpan dalam long-term memory.

Modul yang dirancang lengkap dengan memuat satu set bahan instruksional dalam kemasan terkecil dilihat dari lingkup isi, namun mengandung semua unsur dalam sistem instruksional, sehingga dapat dipelajari secara terpisah dari modul lain ini dapat digunakan secara fleksibel sesuai dengan kebutuhan si belajar [2]. Modul yang digunakan siswa dalam pembelajaran ditampilkan dalam gambar berikut.

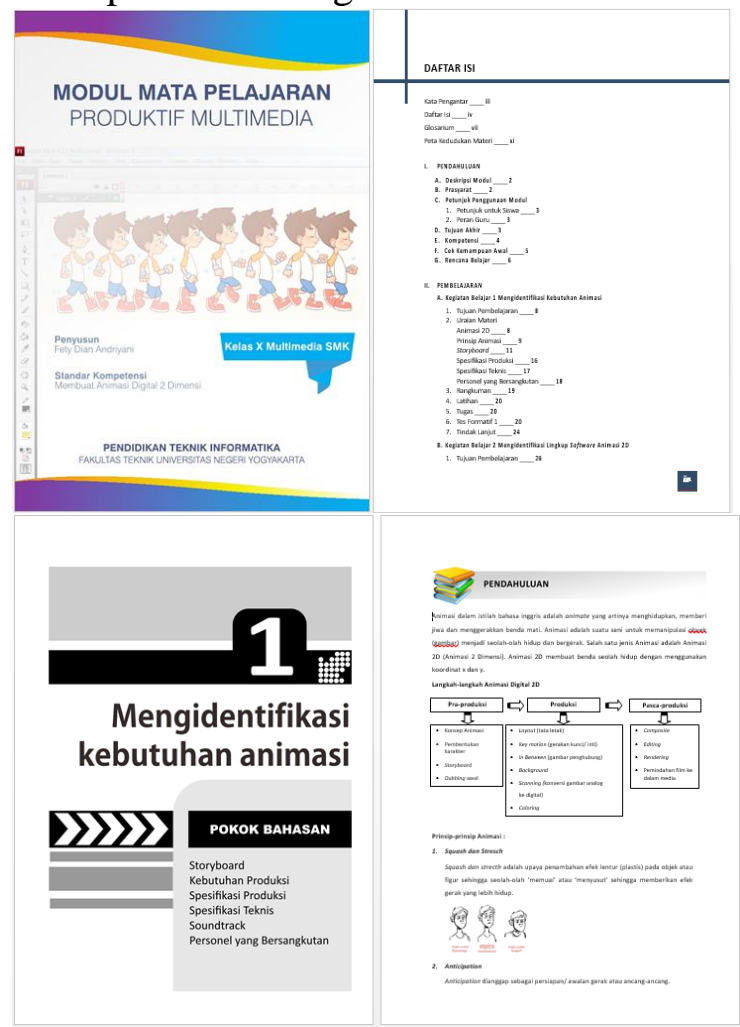

\section{Gambar 5. Tampilan Modul Pembelajaran}

Modul tersusun dari beberapa kegiatan belajar yang meliputi materi, kegiatan praktik, kesimpulan, tugas, dan latihan soal. Pemanfaatan modul pembelajaran berbasis proyek efektif untuk menunjang pembelajaran khususnya pembelajaran praktik mata pelajaran Produktif Multimedia siswa SMK. Selain itu, modul ini juga membantu siswa untuk melakukan evaluasi diri terhadap tingkat penguasaan materi yang telah dipelajari [14]. Bagi guru, modul juga bermanfaat karena dapat membantu siswa dalam memahami suatu informasi dan memecahkan masalah, modul juga memperluas wawasan karena disusun dengan menggunakan berbagai referensi, menambah cakupan pengetahuan 
dan pengalaman dalam menulis bahan ajar, serta membangun komunikasi yang efektif antara dirinya dengan siswa.

\section{SIMPULAN}

Simpulan penelitian ini adalah modul pembelajaran berbasis proyek pada mata pelajaran Produktif Multimedia untuk siswa SMK dapat dijadikan sebagai sumber belajar mandiri dan fleksibel. Pembelajaran menggunakan modul ini terbukti signifikan dan cukup efektif untuk meningkatkan hasil belajar siswa khususnya pada mata pelajaran Produktif Multimedia materi Animasi 2 Dimensi kelas X Semester 2.

Adanya perbedaan hasil belajar siswa antara sebelum dan sesudah menggunakan modul pembelajaran berbasis proyek pada mata pelajaran Produktif Multimedia. Selain itu, tingkat keefektifan modul pembelajaran berada pada kategori sedang, dengan interpretasi cukup efektif digunakan sebagai sumber belajar siswa. Lebih lanjut, siswa diharapkan dapat menggunakan modul pembelajaran berbasis proyek secara disiplin dan terarah, agar memperoleh hasil belajar yang lebih baik serta mampu mengembangkan diri secara maksimal dengan bantuan modul. Pada penelitian selanjutnya, pengujian efektivitas modul pembelajaran tidak hanya untuk menilai hasil belajar secara kognitif siswa, tetapi juga pada penilaian hasil kerja siswa untuk ranah afektif dan psikomotor.

\section{DAFTAR PUSTAKA}

[1] N. S. Degeng. Ilmu Pembelajaran: Klasifikasi Variabel untuk Pengembangan Teori dan Penelitian. Bandung: Kala Hidup, 2013.

[2] M. A. Suparman. Desain Instrusional Modern: Panduan Para Pengajar dan Inovator Pendidikan. Jakarta: Erlangga, 2014.
[3] "Data Pokok SMK." http://datapokok.ditpsmk.net/ (accessed Jul. 10, 2020).

[4] Presiden Republik Indonesia, Peraturan Pemerintah Nomor 17 Tahun 2010 tentang Pengelolaan dan Penyelenggaraan Pendidikan. 2010.

[5] Sutirman. "Pengembangan E-module Berbasis Experiental Learning untuk Pembelajaran Manajemen Arsip Elektronik di SMK". Disertasi, Universitas Negeri Yogyakarta, 2017.

[6] P. Y. A. Dewi dan K. H. Primayana. "Effect of Learning Module with Setting Contextual Teaching and Learning to Increase the Understanding of Concepts". International Journal of Education and Learning, vol. 1, no. 1, pp. 1926, Jun. 2019.

[7] V. L. P. Sutrisno. "Faktor-Faktor yang Mempengaruhi Hasil Belajar Siswa pada Pembelajaran Praktik Kelistrikan Otomotif SMK di Kota Yogyakarta". vol. 6, no. 1, pp. 111120, Feb. 2016.

[8] S. Sulistiyani. "Pengaruh Modul Pembelajaran Berbasis Problem Based Learning terhadap Hasil Belajar". SAP Susunan Artik. Pendidik., vol. 2, no. 2, Dec. 2017, Accessed: Jul. 10, 2020. [Online]. Available:

https://journal.lppmunindra.ac.id/ind ex.php/SAP/article/view/2086.

[9] D. Septiani, W. Sumarni, dan Saptorini. "Efektivitas Model Inkuiri Berbantuan Modul dalam meningkatkan Pemahaman Konsep dan Keterampilan Generik Sains". Jurnal Inovasi Pendidikan Kimia, vol. 8, no. 2, pp. 1340-1350, 2014.

[10] R. R. Hake. Relationship of Individual Student Normalized Learn Gains in. Mechanics with Gender, High-School Physics, and Pretest 
Scores on Mathematics and Spatial Visualization. 2002.

[11] R. Hake. "Interactive-Engagement Versus Traditional Methods: a SixThousand-Student Survey of Mechanics Test Data for Introductory Physics Courses". Am. J. Phys. - AMER J PHYS, vol. 66, Jan. 1998, doi: 10.1119/1.18809.

[12] H. Chotimah, H. Susilo, and M. H. I. Al Muhdhar, "Development of Biology Modules with Think Pair Share Strategy as an Effort to Improve Cognitive Learning Outcomes of Vocational Students". Int. J. Res. Rev., vol. 4, no. 6, pp. 613, Jun. 2017.

[13] S. Oksa dan S. Soenarto. "Pengembangan E-Modul Berbasis Proyek untuk Memotivasi Belajar Siswa Sekolah Kejuruan". $J$. Kependidikan Penelit. Inov. Pembelajaran, vol. 4, no. 1, pp. 99111, May 2020.

[14] A. Prastowo. Panduan Kreatif Membuat Bahan Ajar Inovatif. Yogyakarta: Diva Press, 2011. 